\title{
Estudo da germinação e crescimento in vitro de Hadrolaelia tenebrosa (Rolfe) Chiron \& V.P. Castro (Orchidaceae), uma espécie da flora brasileira ameaçada de extinção
}

\author{
Rogério Mamoru Suzuki ${ }^{1,4}$, Vania Carolina Moreira ${ }^{1}$, Myna Nakabashi $^{2}$ e Wagner de Melo Ferreira ${ }^{3}$
}

Recebido: 28.05.2009; aceito: 06.11.2009

\begin{abstract}
In vitro germination and growth of Hadrolaelia tenebrosa (Rolfe) Chiron \& V.P. Castro (Orchidaceae), an endangered species of the Brazilian flora). Orchids are seriously endangered species. For that reason, studies regarding their propagation and development are extremely important. Thus, the present study analyzed the influence of the culture medium on the in vitro germination of Hadrolaelia tenebrosa seeds, on the initial development of protocorms until they form seedlings and on seedling growth during the first twelve months in vitro. The results revealed that the ideal methodology for the in vitro culture of Hadrolaelia tenebrosa involves the use the Knudson's C medium for seed germination and seedling initial growth, and the subsequent transfer of six-month-old plants to VW medium where they should remain until acclimatization is carried out. The obtained data showed that the most efficient culture medium for seed germination of that species was not the most adequate for the development of their seedlings. Therefore, the outcomes of such studies are very important for the optimization of propagation techniques for orchid species.
\end{abstract}

Key words: asymbiotic germination, in vitro culture, media culture, orchid

RESUMO - (Estudo da germinação e crescimento in vitro de Hadrolaelia tenebrosa (Rolfe) Chiron \& V.P. Castro (Orchidaceae), uma espécie da flora brasileira ameaçada de extinção). As orquídeas são espécies seriamente ameaçadas de extinção. Por isso, estudos sobre a propagação e desenvolvimento dessas plantas são extremamente importantes. Assim, este trabalho procurou estudar a influência do meio de cultura na germinação in vitro de sementes de Hadrolaelia tenebrosa, no desenvolvimento inicial dos protocormos até a formação das plântulas, bem como no crescimento dessas durante o primeiro ano de cultivo in vitro. Os resultados demonstraram que o método ideal para a multiplicação de Hadrolaelia tenebrosa é a utilização do meio Knudson C para a germinação das sementes. Após seis meses as plântulas devem ser transferidas para o meio VW e nele mantidas até o início da aclimatização. Ressalta-se o fato de que para essa espécie o meio de cultura mais eficaz para a germinação, não foi o mais adequado para o desenvolvimento das plantas. Estas informações são de grande importância para a otimização do processo de propagação de espécies de orquídeas.

Palavras-chave: cultivo in vitro, germinação assimbiótica, meios de cultura, orquídea

\section{Introdução}

A família Orchidaceae (Orchidales, Liliopsida) compreende mais de 25.000 espécies distribuídas em 800 gêneros (Atwood 1986, Chase et al. 2003). Seus representantes possuem diferentes hábitos; há espécies terrícolas, epífitas, rupícolas, escandentes ou até mesmo saprófitas. Isso possibilita uma distribuição cosmopolita, embora sejam mais abundantes e diversificadas em florestas tropicais (Pinheiro et al. 2004). Cada espécie de orquídea possui adaptações para ocupar um ambiente específico, e devido as suas especializações, muitas possuem distribuição restrita e o endemismo é bastante elevado (Pritchard 1989). As orquídeas apresentam frutos com milhares de sementes, contudo a germinação destas é pouco eficiente em condições naturais, chegando ao máximo em 5\% (Stoutamire 1964).

Não obstante o fato de serem membros da maior família de plantas com flores, as orquídeas estão entre as mais seriamente ameaçadas de extinção, sendo que a vulnerabilidade resultaria de várias

1. Instituto de Botânica, Seção de Orquidário do Estado, Av. Miguel Stéfano 3687, 04301-902 São Paulo, SP, Brasil

2. Universidade de São Paulo, Instituto de Biociências, Rua do Matão Travessa 14, 321, 05508-900 São Paulo, SP, Brasil

3. Universidade Federal do Tocantins, Núcleo de Estudos Ambientais (Neamb), Caixa Postal 111,77500-000 Porto Nacional, TO, Brasil

4. Autor para correspondência: rogeriomsuzuki@yahoo.com.br 
razões, as principais seriam: o ciclo de vida altamente especializado, como por exemplo, longo período vegetativo até atingir o período reprodutivo, sementes com pouca ou nenhuma reserva, a germinação de sementes dependente da associação com fungos micorrízicos, e a ação do homem por meio da destruição do habitat, derrubando árvores e florestas, além da coleta indiscriminada de orquídeas na natureza (Ferreira \& Suzuki 2008). No Brasil, não só com relação às orquídeas, mas também às demais espécies, a preocupação com o aumento do número de espécies ameaçadas de extinção é crescente. A possibilidade de produzir plantas de orquídeas em grandes quantidades poderia garantir que essas plantas ocupem um lugar no futuro, evitando sua extinção (Suzuki \& Ferreira 2007).

Hadrolaelia tenebrosa (Rolfe) Chiron \& V.P. Castro, espécie objeto do presente estudo, possui flores de aspecto bastante vistoso, apresentando sépalas e pétalas que variam do marrom ao bronze. O labelo possui venações de cor púrpura formando um anel púrpuro-escuro. Cada inflorescência apresenta até seis flores por haste, sendo que o tamanho da flor pode ultrapassar $20 \mathrm{~cm}$ (Hoehne 1949), constituindose numa espécie de grande interesse comercial. Tais características impulsionaram a extração desta espécie na natureza, levando ao quadro atual de espécie ameaçada de extinção da flora brasileira, de acordo com a instrução normativa número seis, de 23 de setembro de 2008, do Ministério do Meio Ambiente, categorizando-a como espécie com alto risco de desaparecimento na natureza em futuro próximo.

Estudos que visem melhorar o processo de propagação e desenvolvimento de orquídeas são extremamente importantes não apenas para que se possa dominar seu cultivo, mas também para preserválas e assim evitar sua extinção. Neste sentido, as técnicas de cultivo in vitro são comprovadamente eficientes na melhoria da taxa de germinação de sementes de várias espécies desta família, na multiplicação dos indivíduos, além de produzir plantas com excelente qualidade fitossanitária. Por meio desse processo sementes são induzidas a germinarem em meio de cultura sob condições assépticas, mantidas em sala de crescimento onde fatores ambientais como luz e temperatura são adequadamente controlados (Torres et al. 1998).

O presente trabalho teve como objetivo estudar a influência do meio de cultura na germinação in vitro de sementes de Hadrolaelia tenebrosa, no desenvolvimento inicial dos protocormos até a formação das plântulas, bem como no crescimento dessas durante o primeiro ano de cultivo in vitro.

\section{Material e métodos}

Considerações taxonômicas sobre Hadrolaelia tenebrosa - o gênero Hadrolaelia possui muitos sinônimos e várias seções amplamente reconhecidas no passado. Atualmente, existem controvérsias com relação a sua qualificação taxonômica, uma vez que durante muito tempo foi utilizado o epíteto genérico Laelia. Entretanto em 2000 foi reclassificada como Sophronitis, por Van den Berg \& Chase (2000) e posteriormente Chiron \& Castro Neto (2002) apresentaram uma nova classificação (adotada neste trabalho) para as espécies deste gênero, qualificando a espécie como Hadrolaelia tenebrosa.

Germinação e análise do desenvolvimento "in vitro" - plantas de H. tenebrosa foram selecionadas da coleção da Seção de Orquidário "Frederico Carlos Hoehne", no Instituto de Botânica, e utilizadas para a polinização cruzada. As sementes foram retiradas de frutos maduros, ou seja, oito meses após a polinização das flores, e armazenadas a $4{ }^{\circ} \mathrm{C}$, durante cerca de $24 \mathrm{~h}$ para a semeadura in vitro. As sementes foram embebidas em água destilada e esterilizada durante trinta minutos, e posteriormente tratadas com solução de $15 \%\left(\mathrm{v} \mathrm{v}^{-1}\right)$ de hipoclorito de sódio comercial (2\%$2,5 \%$ de cloro) durante dez minutos. Em seguida, com o auxílio de uma micropipeta e ponteiras esterilizadas, a solução de hipoclorito foi retirada e as sementes lavadas três vezes em água destilada e esterilizada, sendo subseqüentemente inoculadas em três meios de cultura: o meio VW (Vacin \& Went 1949), modificado pela substituição do $\mathrm{Fe}_{2}\left(\mathrm{C}_{4} \mathrm{H}_{4} \mathrm{O}_{6}\right)_{3}$ pelo $\mathrm{Fe}$-EDTA, o meio MS (Murashige \& Skoog 1962) e o meio KN (Knudson 1946), suplementados com 2\% de sacarose e micronutrientes do meio MS, e geleificados com 0,4\% de ágar bacteriológico. O sulfato de manganês foi adicionado separadamente ao meio $\mathrm{KN}$ devido à menor concentração desse micronutriente na composição desse meio de cultura.

$\mathrm{O} \mathrm{pH}$ dos meios de cultura foi ajustado para 5,8 $\pm 0,05$, anteriormente à adição de $0,4 \%$ de ágar. Após a homogeneização, foram distribuídos em frascos de vidro de $200 \mathrm{~mL}$, sendo que em cada frasco foram colocados $40 \mathrm{~mL}$ de meio de cultura. A esterilização dos meios foi realizada em autoclave a $120{ }^{\circ} \mathrm{C}$ e 1,3 atm durante 15 minutos.

O delineamento experimental utilizado foi o inteiramente ao acaso com três frascos (repetições) para 
cada meio de cultura, os quais foram mantidos em sala de cultura com temperatura média de $25 \pm 2^{\circ} \mathrm{C}$, fotoperíodo de 12 horas e intensidade luminosa de aproximadamente 20 umol. $\mathrm{m}^{2} . \mathrm{s}^{-1}$ obtida com lâmpadas fluorescentes.

Trinta dias após a inoculação das sementes, foi realizada a análise da taxa de germinação (germinabilidade), obtendo-se a porcentagem de sementes germinadas e não germinadas, a partir da retirada de três amostras de cada um dos frascos dos diferentes meios de cultura. Cada amostra foi depositada sobre uma lâmina quadriculada e todas foram analisadas em estereomicroscópio (aproximadamente 3.500 sementes de cada tratamento). Foram consideradas germinadas as sementes com embrião intumescido e clorofilado, características do estádio de protocormo em orquídeas. Os dados em porcentagem foram transformados em $\operatorname{arcsen}(\mathrm{x}+10)^{1 / 2}$ e submetidos à análise de variância (ANOVA), seguido do teste de Tukey em nível de 5\% de significância $(\mathrm{p}<0,05)$.

Após 120 e 180 dias da inoculação das sementes, 500 amostras de cada tratamento, foram retiradas e avaliadas quanto às diferentes fases do desenvolvimento inicial. Esse método foi modificado a partir dos trabalhos de Milaneze (1997) e Stewart \& Kane (2006). Assim, foram considerados quatro estádios distintos de desenvolvimento (Figura 1): a) estádio 1 = protocormo intumescido clorofilado, $b$ ) estádio 2 = plântula com formação da primeira folha, c) estádio 3 = plântula com duas ou mais folhas, d) estádio 4 = plântula com folhas e uma ou mais raízes.

Para o estudo sobre o crescimento 'posterior' de plantas, foram utilizadas plantas com 180 dias de cultivo após a inoculação das sementes, que possuíam o mesmo comprimento $(1 \pm 0,2 \mathrm{~cm}$ de altura, medida da base do caule até a extremidade da folha maior). Estas plantas foram transferidas para frascos de cultura de $400 \mathrm{~mL}$ contendo $80 \mathrm{~mL}$ de meio para cada tratamento (KN, MS e VW), e mantidas nas mesmas condições ambientais citadas anteriormente. Para cada tratamento foram utilizados três frascos (repetições) contendo quinze plântulas. Ao final de mais seis meses de cultivo quarenta plantas de cada tratamento foram retiradas aleatoriamente e analisadas em relação ao número de folhas e raízes formadas, quanto ao comprimento caulinar (considerando a medida da base do caule até a extremidade da folha maior) e da maior raiz, além da massa de matéria fresca e seca das porções caulinar e radicular, separadamente. Para cada parâmetro de crescimento analisado foi realizado tratamento estatístico a partir da análise de variância
(ANOVA), seguido do teste de separação das médias utilizando-se o teste de Tukey em nível de 5\% de significância.

\section{Resultados e Discussão}

O início da germinação das sementes foi observado por meio da visualização do intumescimento dos embriões e produção de clorofila pelos protocormos, decorridos vinte dias da inoculação das sementes. Segundo Muñoz \& Jimenez (2008), a preferência pela utilização de sementes oriundas de frutos maduros ao invés de frutos imaturos decorre do fato de haver maior quantidade de sementes viáveis em frutos maduros do que naqueles provenientes de frutos imaturos, apesar do possível aumento da contaminação e danos provocados pela desinfestação de sementes de frutos maduros. Para $H$. tenebrosa a contaminação foi $6,6 \%$, considerada aceitável, em termos de eficiência.

Os resultados da germinabilidade estão expressos na tabela 1. A utilização do meio $\mathrm{KN}$ propiciou a obtenção da maior taxa de germinação de sementes de $H$. tenebrosa (67\%). A taxa de germinação no meio $\mathrm{KN}$ foi significativamente superior quando comparada com a do meio VW $(60 \%)$. O meio MS apresentou uma taxa de germinação (61\%) estatisticamente intermediária entre os meios $\mathrm{KN}$ e VW. Uma maior taxa de germinação com o meio KN também foi observada por Kohl (1962), estudando a germinação de diferentes espécies de Cymbidium. Lo et al. (2004) utilizando os mesmos meios de cultura obtiveram plantas apenas quando sementes de Dendrobium tosaense foram inoculadas no meio MS, não verificando sequer a formação de protocormos quando utilizaram o meio $\mathrm{KN}$ e $\mathrm{VW}$.

Tabela 1. Germinabilidade de sementes de Hadrolaelia tenebrosa obtida trinta dias após a semeadura in vitro. Letras diferentes apresentam variação significativa entre os tratamentos, segundo teste de Tukey $(\mathrm{P}<0,05)$, $(\mathrm{n}=3500)$.

Table 1. Seed germination percentage of Hadrolaelia tenebrosa thirty days after in vitro sowing. Values followed by the same letters are not significantly different, according to the Tukey test $(\mathrm{P}<0.05)$. $(\mathrm{n}=3,500)$.

\begin{tabular}{ll}
\hline Meios de cultura & Germinabilidade (\%) \\
\hline KN - Knudson (1946) & $67,0 \mathrm{a}$ \\
MS - Murashige \& Skoog (1962) & $61,0 \mathrm{ab}$ \\
VW - Vacin \& Went (1949) & $60,0 \mathrm{~b}$ \\
\hline
\end{tabular}



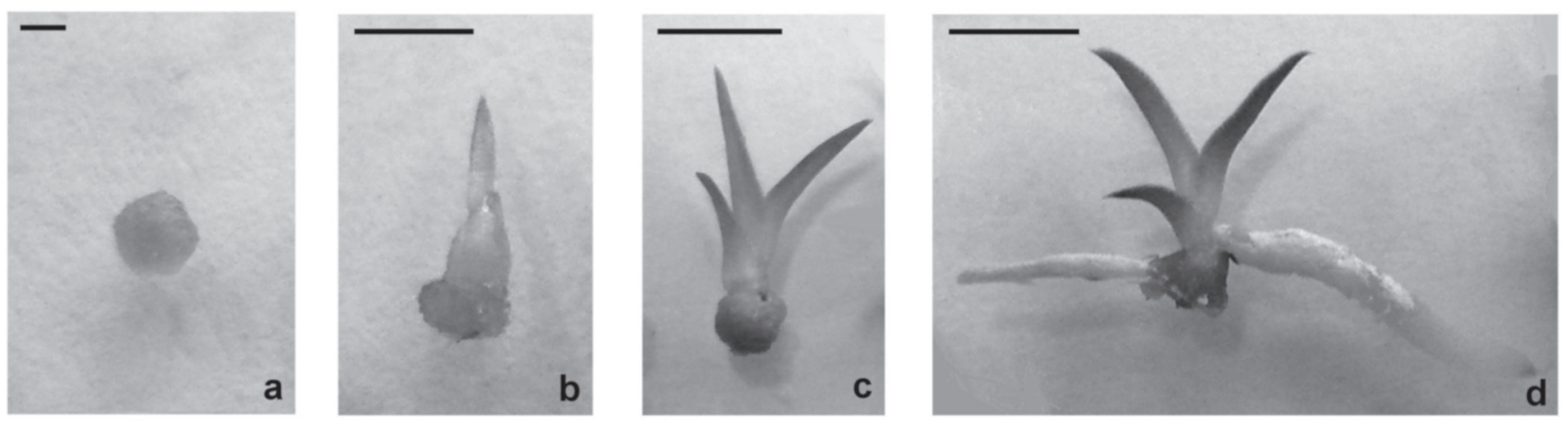

Figura 1. Morfologia geral dos estádios de desenvolvimento de protocormos até a formação de plântulas de Hadrolaelia tenebrosa. a) Estádio 1 = protocormo intumescido clorofilado, b) estádio 2 = plântula com formação da primeira folha, c) estádio $3=$ plântula com duas ou mais folhas, d) estádio 4 = plântula com folhas e uma ou mais raízes. Barras de escala a =0,5 mm; b,c,d = 0,5cm.

Figure 1. General morphology of the developmental stages of Hadrolaelia tenebrosa protocorms until seedling formation. a) Stage $1=$ chlorophylled swelled protocorm, b) stage 2 = seedling exhibiting the first leaf, c) stage $3=$ seedling with two or more leaves, d) stage 4 $=$ seedling with leaves and one or more roots. Scale bars: $\mathrm{a}=0.5 \mathrm{~mm} ; \mathrm{b}, \mathrm{c}, \mathrm{d}=0.5 \mathrm{~cm}$.

A escolha do meio de cultura é importante para o processo de germinação e varia entre espécies. $\mathrm{O}$ meio $\mathrm{KN}$ foi o mais favorável para a germinação das sementes de H. tenebrosa, mas em Gongora quinquenervis este mesmo meio provocou a necrose de todos os protocormos formados (Martini et al. 2001). Outro fator que também deve ser considerado é a relação entre os nutrientes e sua influência na germinação. Kauth et al. (2006), por exemplo, observaram em Calopogon tuberosus que o uso de meios de cultura com maior concentração de amônia em relação ao nitrato proporciona melhor germinação das sementes de orquídeas quando comparado aos meios contendo maior concentração de nitrato. No caso de $H$. tenebrosa, o meio $\mathrm{KN}$, que apresentou melhor taxa de germinação contém uma relação nitrato/amônia igual a 1,2, sendo que, possivelmente esta espécie necessite de uma concentração de nitrato semelhante à de amônia uma vez que os outros meios possuem uma relação nitrato/amônia favorecendo a amônia, no meio VW $(0,69)$, ou o nitrato, no meio MS $(1,9)$. As orquídeas que respondem à germinação in vitro podem ser divididas em dois grandes grupos de acordo com suas necessidades nutricionais básicas (Stewart 1989). No primeiro encontram-se as orquídeas cujas sementes germinam em meios de cultura menos complexos como o KN e o VW (1949). O segundo engloba as espécies que necessitam de meios com maior quantidade de macronutrientes como o MS. Os resultados mostraram que $H$. tenebrosa parece pertencer ao primeiro grupo, uma vez que os melhores resultados foram obtidos no meio KN. Além disso, ela é uma espécie epifítica e habita normalmente ambientes oligotróficos o que pode ser relacionado com um meio de cultura menos rico em nutrientes. Entretanto, não foram observadas diferenças significativas entre os meios VW e MS. É possível que neste caso a relação amônia/nitrato nesses dois meios, não favorável à germinação das sementes dessa espécie, tenha comprometido o desempenho germinativo das mesmas, especialmente a aquela do meio VW.

Outro fator que deve ser considerado é que de uma maneira geral as sementes de orquídeas não apresentam endosperma e cotilédone; gotículas de lipídios são as únicas substâncias de reserva contidas no embrião. Esses lipídios são utilizados durante a germinação e citocininas são necessárias para a mobilização dos lipídios (Manning \& Van Staden 1987). As sementes de H. tenebrosa germinaram em meios destituídos de citocininas, o que indica que essas sementes já possuem um adequado nível endógeno dessa classe hormonal.

Os resultados do experimento sobre o estudo do desenvolvimento inicial dos protocormos após 120 dias de semeadura in vitro, nos diferentes meios de cultura são mostrados na figura $2 \mathrm{~A}$. Observando-se a figura é possível notar que os protocormos no meio $\mathrm{KN}$ encontravam-se principalmente no estádio 2, cerca de $49 \%$, entretanto, $38 \%$ dos protocormos estavam no primeiro estádio. Com relação às sementes inoculadas no meio MS, a maior parte dos protocormos 

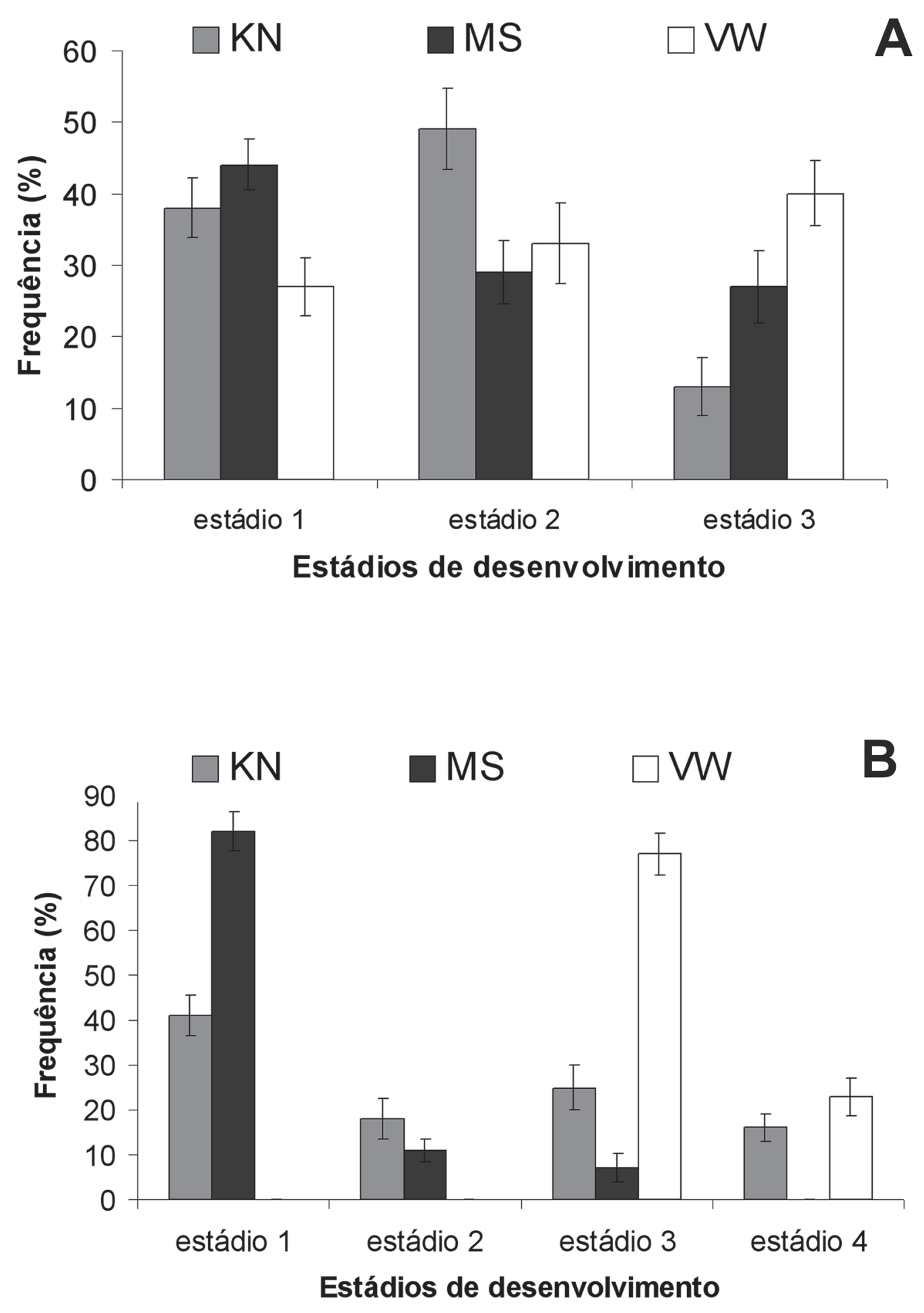

Figura 2. Efeitos de diferentes meios de cultura no desenvolvimento inicial de protocormos de Hadrolaelia tenebrosa A) quatro meses após a semeadura in vitro e B) seis meses após a semeadura in vitro. Estádio 1 = protocormo intumescido clorofilado, estádio $2=$ plântula com formação da primeira folha, estádio 3 = plântula com duas ou mais folhas, estádio 4 = plântula com folhas e uma ou mais raízes (n = 500).

Figure 2. Effects of different culture media on the initial development of Hadrolaelia tenebrosa protocorms. (A) 120 and (B) 180 days after in vitro seed inoculation. Stage $1=$ chlorophylled swelled protocorm, stage $2=$ seedling exhibiting the first leaf, stage $3=$ seedling with two or more leaves, stage $4=$ seedling with leaves and one or more roots $(n=500)$ 
permaneceu no primeiro estádio de desenvolvimento, $44 \%$, sendo que os estádios 2 e 3 representaram, respectivamente $29 \%$ e $27 \%$ dos protocormos em desenvolvimento. Já as sementes germinadas no meio VW apresentaram a maior porcentagem, $40 \%$, no estádio 3, ou seja, plântulas com duas ou mais folhas, caracterizando um desenvolvimento mais rápido. Da mesma forma, a análise do desenvolvimento inicial realizada por Stewart \& Kane (2006) em sementes de Habenaria macroceratitis, após sete semanas, mostrou que entre os meios KN, MS e VW, o meio VW foi o que apresentou maior número de plântulas nos estádios mais avançados e o meio $\mathrm{KN}$ foi o que mostrou o desenvolvimento mais lento.

Os resultados do desenvolvimento inicial dos protocormos, decorridos 180 dias da semeadura in vitro, são mostrados na figura $2 \mathrm{~B}$. O meio $\mathrm{KN}$ embora tenha apresentado protocormos e plantas em todas as fases de desenvolvimento, exibiu a maior parte dos protocormos no estádio 1 (41\%). No meio MS, na análise realizada aos quatro meses, as sementes germinadas apresentaram a maior porcentagem de protocormos na fase inicial de desenvolvimento, ou seja, estádio $1(82 \%)$. Além disso, não foram observadas plântulas no estádio 4 , indicando que nesse meio de cultura os protocormos apresentam desenvolvimento muito lento.

No meio VW verificou-se que as plântulas estavam no estádio 3 (77\%) ou 4 (23\%). Comparando-se com os outros meios de cultura, o VW apresentou ainda a maior porcentagem de plântulas com formação de raízes e tendo duas ou mais folhas, sugerindo que este meio, estimula mais rapidamente o desenvolvimento.

Segundo Kraus et al. (2006), os protocormos originados a partir da germinação de sementes de Catasetum pileatum apresentaram os primórdios radiculares aos 60 dias de cultivo no meio de Knudson (1946). Assim como H. tenebrosa, a maioria das espécies de orquídeas apresenta aparecimento de raízes posteriormente ao surgimento das folhas. Além disso, em protocormos de várias espécies de orquídeas a primeira raiz forma-se adjacente ao meristema caulinar (Nishimura 1981).

Os resultados observados no meio $\mathrm{VW}$ aos 180 dias foram interessantes, pois mostraram a mesma tendência observada na análise aos quatro meses, ou seja, o meio de VW apresentou maior porcentagem de plantas nos estádios mais avançados de desenvolvimento, mostrando-se superior ao meio MS e KN. No estudo realizado por Stewart \& Kane (2006), o meio MS foi o que proporcionou o desenvolvimento mais rápido dos protocormos de Habenaria macroceratitis quando comparados aos outros meios, embora seus experimentos tenham sido mantidos por 16 semanas de cultivo, que representa um período muito curto para avaliações conclusivas.

Resultados diferentes foram encontrados por Stenberg \& Kane (1998), cultivando Encyclia boothiana in vitro. Foi observado que após aproximadamente 90 dias os protocormos no meio VW se tornavam aclorofilados, e que aos 120 dias morriam. De acordo com Stenberg \& Kane (1998), é possível que o fator desencadeador desse processo seja a alta concentração de fosfato de cálcio tribásico $\left(\mathrm{Ca}_{3}\left(\mathrm{PO}_{4}\right)_{2}\right)$, no meio VW, sendo a Encyclia boothiana mais sensível a este composto do que Habenaria macroceratitis (Stewart \& Kane 2006) e Hadrolaelia tenebrosa no presente trabalho.

A análise conjunta sobre a germinação de sementes e o estudo do desenvolvimento inicial mostrou que o meio de cultura que promoveu a maior taxa de germinação, ou seja, o meio KN, não foi o mais eficaz para o posterior desenvolvimento das plantas, o qual ocorreu de forma mais acentuada utilizando-se o meio VW.

São apresentados a seguir os resultados relativos ao crescimento de plantas que foram cultivadas in vitro durante seis meses, a partir da inoculação de plantas que já apresentavam 180 dias de idade após a semeadura in vitro.

Analisando-se a figura 3A é possível perceber que o comprimento caulinar não apresentou diferença significativa entre os meios utilizados. Além disso, nos meios KN e MS o comprimento do caule (1,47 e 1,44 $\mathrm{cm}$, respectivamente) foi maior do que o da raiz (1,32 e $1,15 \mathrm{~cm}$, respectivamente). Contudo no meio VW o comprimento da raiz $(2,0 \mathrm{~cm})$ foi significativamente maior do que os demais meios de cultura. Resultados obtidos por Rego-Oliveira \& Faria (2005), com plantas de Catasetum fimbriatum e Cyrtopodium paranaensis, incubadas durante seis meses em diferentes meios de cultura, foram diferentes aos obtidos para $H$. tenebrosa. O meio MS foi comparativamente aos meios de $\mathrm{KN}$ e VW o que mais estimulou o aumento do comprimento de caules e raízes em Catasetum fimbriatum. Entretanto para a espécie Cyrtopodium paranaensis o maior comprimento caulinar foi obtido no meio MS, enquanto que o maior tamanho radicular foi obtido em plantas incubadas no meio KN. Majerowicz et al. (2000), verificaram que dentre as fontes inorgânicas utilizadas no crescimento de Catasetum fimbriatum, o meio contendo uma relação 

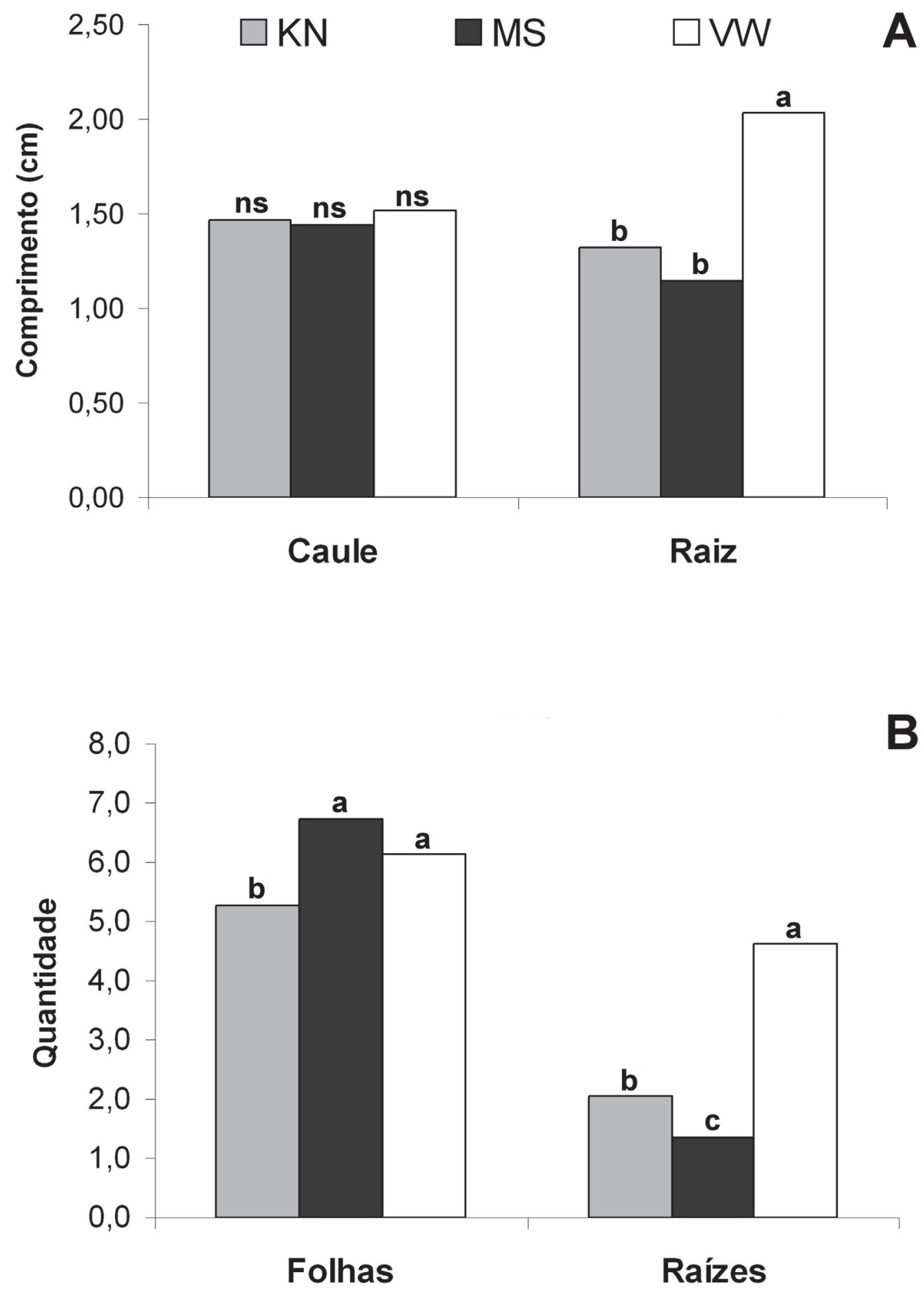

Figura 3. Efeitos de diferentes meios de cultura no comprimento de caules e da raiz maior (A) e no número de folhas e raízes (B) de Hadrolaelia tenebrosa após 180 dias de cultivo in vitro. Barras seguidas de letras diferentes apresentam variação significativa entre os tratamentos, segundo teste de Tukey $(\mathrm{P}<0,05)$. Barras seguidas de "ns" não apresentaram variação significativa entre os tratamentos $(\mathrm{n}=40)$.

Figure 3. Effects of different culture media on shoot and longest root length (A) and on the number of leaves and roots (B) of Hadrolaelia tenebrosa after 180 days of in vitro culture. Vertical bars with different letters are significantly different, according to the Tukey $(\mathrm{P}<$ $0.05)$. Vertical bars with "ns" did not show significant variation between treatments $(n=40)$. 
nitrato/amônia de 2:3, foi o que promoveu um maior crescimento das plantas quando comparados aos meios de cultura contendo nitrato ou amônia isoladamente como fonte de nitrogênio. Esses autores concluíram que para o crescimento desta espécie a amônia é a principal fonte de nitrogênio.

Analisando-se a figura 3B é possível verificar que os meios MS e VW foram significativamente mais eficazes na produção de folhas $(6,7$ e 6,1 respectivamente) do que o $\mathrm{KN}(5,3)$. Com relação às raízes, houve um aumento significativo do número de raízes nas plantas cultivadas no meio VW $(4,6)$; sendo o meio MS $(1,3)$ bastante prejudicial para a formação de raízes. Este último parâmetro foi divergente do obtido por Rego-Oliveira \& Faria (2005), que observaram maior quantidade de raízes em Catasetum fimbriatum quando utilizaram o meio MS, enquanto que em Cyrtopodium paranaensis, o maior número de raízes foi obtido quando cultivada no meio $\mathrm{KN}$.

A ação dos meios de cultura no acúmulo de massa de matéria fresca de caules e raízes está expressa na figura 4A, na qual se observa que nos meios MS e VW os caules de $H$. tenebrosa obtiveram maior ganho de massa de matéria fresca $(98,4$ e $93,1 \mathrm{mg}$, respectivamente) quando comparado ao obtido em KN $(73,3 \mathrm{mg})$. Com relação às raízes, houve maior acúmulo quando utilizado o meio $\mathrm{VW}$, sendo o meio MS o que menos favoreceu esse parâmetro.

A figura 4B exibe a massa de matéria seca das plantas de $H$. tenebrosa após 180 dias de cultivo nos diferentes meios de cultura. Estes resultados são semelhantes aos obtidos para massa de matéria fresca caulinar, diferindo apenas quando analisados os resultados de análise de variância. Neste caso, o meio MS estimulou significativamente o acúmulo de matéria seca dos caules $(6,7 \mathrm{mg})$, em relação apenas ao meio $\mathrm{KN}$ (5,3 mg), uma vez que no meio VW os valores obtidos foram intermediários $(6,1 \mathrm{mg})$. O meio VW favoreceu significativamente o acúmulo de massa de matéria seca das raízes $(4,6 \mathrm{mg})$, contrariamente, o meio MS não favoreceu esse parâmetro $(1,3 \mathrm{mg})$.

Resultados diferentes foram obtidos por RegoOliveira e Faria (2005) para duas espécies estudadas: Cyrtopodium paranaensis apresentou maior acúmulo de massa de matéria seca caulinar no meio MS e menor no meio VW. Esses autores observaram ainda que o acúmulo de massa de matéria seca radicular foi maior no meio VW e menor no meio KN. Já em Catasetum fimbriatum a maior e menor massa de matéria seca caulinar foi observada nos meios $\mathrm{KN}$ e $\mathrm{VW}$, respectivamente, enquanto que a maior e menor massa de matéria seca radicular foram obtidos no meio MS e VW, respectivamente.

Os dados obtidos neste trabalho indicam que durante o primeiro ano de vida as plantas de $H$. tenebrosa priorizaram o desenvolvimento caulinar, possivelmente de maneira a garantir a energia necessária para o crescimento posterior por meio de processos fotossintéticos, e possivelmente para a formação de novas gemas laterais que proporcionaram crescimento contínuo da porção caulinar e radicular.

Os resultados aqui apresentados apontam que o meio de cultura que promove a germinação de sementes de $H$. tenebrosa não promove o maior desenvolvimento das plantas e que cada etapa do desenvolvimento in vitro desta espécie exige um meio de cultura diferente, confirmando uma exigência nutricional específica. Portanto, a obtenção destas informações é de grande importância para a otimização do processo de propagação assimbiótica de espécies de orquídeas in vitro.

Em resumo, é possível concluir que a metodologia ideal para o cultivo in vitro de plantas de Hadrolaelia tenebrosa, seria o emprego do meio $\mathrm{KN}$ para a germinação das sementes. Após seis meses as plantas devem ser transferidas para o meio VW e mantidas nesse meio até que seja iniciado o processo de aclimatização, por volta de 12 meses após a semeadura.

\section{Agradecimentos}

Agradecemos ao Conselho Nacional de Desenvolvimento Científico e Tecnológico (CNPq) pelo apoio financeiro por meio de bolsa individual de Iniciação à Pesquisa do Programa Institucional de Bolsas de Iniciação Científica - PIBIC, concedida à V. C. Moreira

\section{Literatura citada}

Atwood, J.T. 1986. The size of the Orchidaceae and the systematic distribution of epiphytic orchids. Selbyana 9: 171-186.

Chase, M.W., Cameron, K.M., Barrett, R.L. \& Freudenstein, J.V. 2003. DNA data and Orchidaceae systematics: a new phylogenetic classification. In: K.W. Dixon, S.P. Kell, R.L. Barrett \& P.J. Cribb (eds.). Orchid conservation. Natural History Publications, Sabah, pp. 69-89.

Chiron, G.R. \& Castro Neto, V.P. 2002. Révision des espèces brésiliennes du genre Laelia Lindley. Richardiana 2: 4-28. 

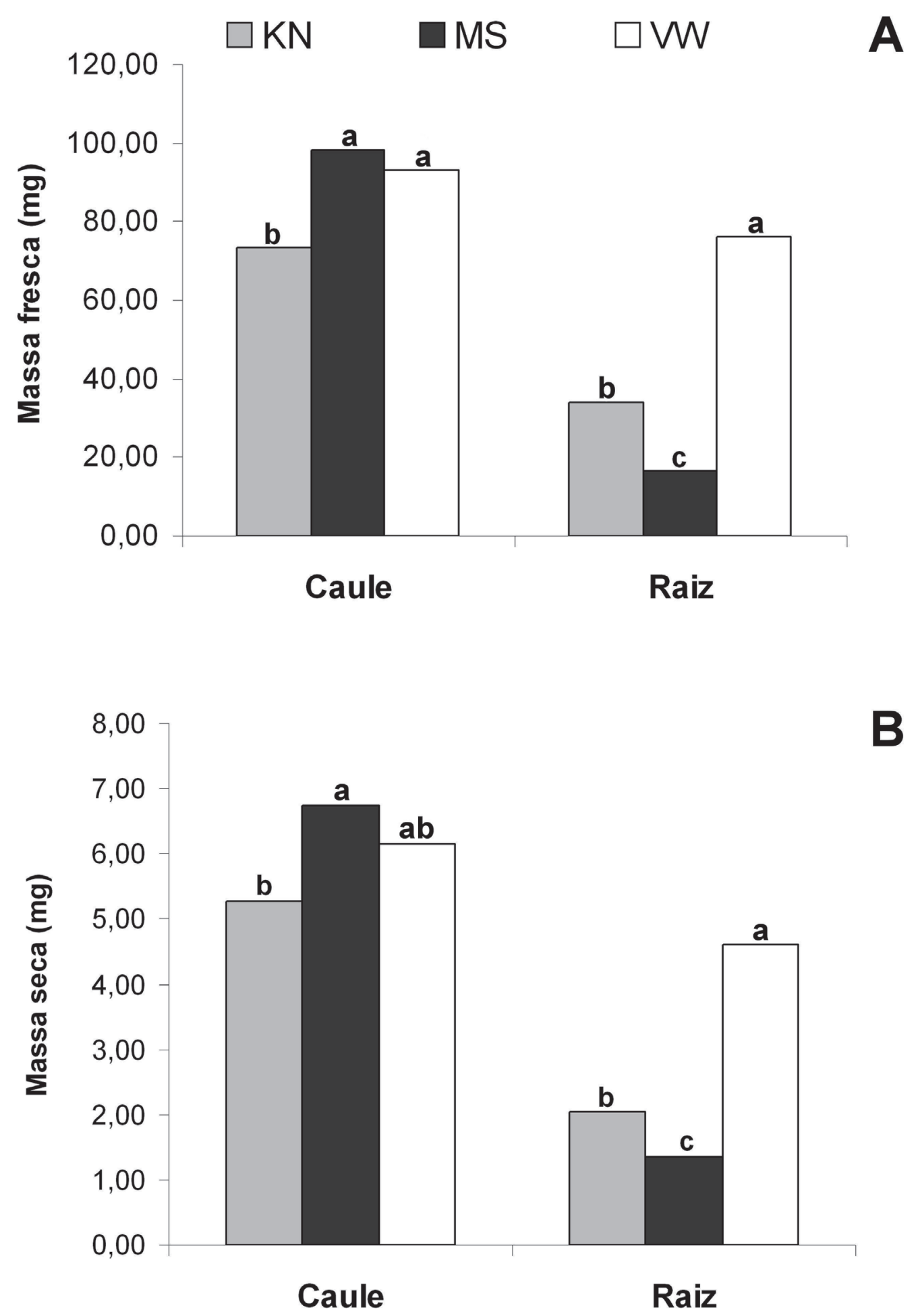

Figura 4. Efeitos de diferentes meios de cultura sobre o acúmulo de massa de matéria fresca (A) e de massa de matéria seca (B) de caules e raízes de Hadrolaelia tenebrosa após 180 dias de cultivo in vitro. Barras seguidas de letras diferentes apresentam variação significativa entre os tratamentos, segundo teste de Tukey $(\mathrm{P}<0,05 ; \mathrm{n}=40)$.

Figure 4. Effects of different culture media on increase of shoot and root fresh matter (A) and on dry matter (B) of Hadrolaelia tenebrosa after 180 days of in vitro culture. Vertical bars with different letters are significantly different, according to the Tukey test $(\mathrm{P}<0.05 ; \mathrm{n}=40)$. 
Ferreira, W.M. \& Suzuki, R.M. 2008. O cultivo in vitro de orquídeas como alternativa para a preservação de espécies nativas ameaçadas de extinção. In: M.I.B. Loiola, I.G. Baseia \& J.E. Lichston (org.). Atualidades, desafios e perspectiva da botânica no Brasil. Imagem Gráfica, Natal, pp. 67-68.

Hoehne, F.C. 1949. Iconografia de Orchidaceas do Brasil. Secretaria de Agricultura, Indústria e Comércio de São Paulo, Departamento de Botânica do Estado, São Paulo.

Kauth,P.J., Vendrame, W.A. \& Kane, M.E. 2006. In vitro seed culture and seedling development of Calopogon tuberosus. Plant Cell, Tissue and Organ Culture 85: 91-102.

Knudson, L. 1946. A new nutrient solution for germination of orchid seeds. American Orchid Society Bulletin 15: 214-217.

Kohl, H.C. 1962. Notes on the development of Cymbidium from seed to plantlet. American Orchid Society Bulletin 31: 117-120.

Kraus, J.E., Kerbauy, G.B. \& Monteiro, W.R. 2006. Desenvolvimento de protocormos de Catasetum pileatum Rchb.f. in vitro: aspectos estruturais e conceituais. Hoehnea 33: 177-184.

Lo,S.H., Nalawade, S.M., Kuo, C.L., Chen, C.L.\& Tsay, H.S. 2004. Asymbiotic germination of immature seeds, plantlet development and ex vitro establishment of plants of Dendrobium tosaense makino - a medicinally important orchid. In Vitro Cellular \& Developmental Biology-Plant 40: 528-535.

Majerowicz, N., Kerbauy, G.B., Nievola, C.C. \& Suzuki, R.M. 2000. Growth and nitrogen metabolism of Catasetum fimbriatum (Orchidaceae) grown with different nitrogen sources. Environmental and Experimental Botany 44: 195-206.

Manning, J.C. \& Van Staden, J. 1987. The development and mobilization of seed reserves in some african orchids. Australian Journal of Botany 35: 343-353.

Martini, P.C., Willadino, L., Alves, G.D. \& Donato, V.M.T.S. 2001. Propagação de orquídea Gongora quinquenervis por semeadura in vitro. Pesquisa Agropecuária Brasileira 36: 1319-1324.

Milaneze, A.M. 1997. Estudos em orquídeas nativas do Brasil: morfologia de sementes e cultivo assimbiótico. Tese de Doutorado, Universidade Estadual Paulista, Rio Claro.

Muñoz, M. \& Jimenez, V.M. 2008. Capsule development, in vitro germination and plantlet acclimatization in Phragmipedium humboldthi, $P$. longifolium and $P$. pearcei. Lankesteriana 8: 23-31.
Murashige, T.\& Skoog, F.A. 1962. A Revised medium for rapid growth and bioassays with tobacco tissue culture. Physiologia Plantarum 15: 473-497.

Nishimura, G. 1981. Comparative morphology of Cattleya and Phalaenopsis (Orchidaceae) seedlings. Botanical Gazette 142: 306-365.

Pritchard, H.W. 1989. Modern methods in orchid conservation: the role of physiology, ecology and management. Cambridge University Press, Cambridge.

Pinheiro, F., Barros, F. \& Lourenço, R.A. 2004. O que é uma Orquídea ? In: F. Barros \& G.B. Kerbauy (org.). Orquidologia Sul-Americana: uma compilação científica. Secretaria do Meio Ambiente/Instituto de Botânica, São Paulo, pp. 11-33.

Rego-Oliveira, L. \& Faria, R.T. 2005 In vitro propagation of Brazilian orchids using traditional culture media and comercial fertilizers formulation. Acta Scientiarum 1: $1-5$.

Stenberg, M.L. \& Kane, M.E. 1998. In vitro seed germination and greenhouse cultivation of Encyclia boothiana var. erythronioides, an endangered Florida orchid. Lindleyana 13: 101-112.

Stewart, S.L. \& Kane, M.E. 2006. Asymbiotic seed germination and in vitro seedling development of Habenaria macroceratitis (Orchidaceae) a rare Florida terrestrial orchid. Plant Cell, Tissue and Organ Culture 86: $147-158$

Stewart, J. 1989. Orchid propagation by tissue culture techniques - past, present and future. In: H.W. Pritchard (ed.). Modern methods in orchid conservation: the role of physiology, ecology and management. Cambridge University Press, Cambridge, pp. 147-183.

Stoutamire, W.P. 1964. Seeds and seedlings of native orchids. Michigan Botanist 3: 107-119

Suzuki, R.M. \& Ferreira, W.M. 2007. Introdução às técnicas de micropropagação de orquídeas. In: L.M. Barbosa \& N.A. Santos Jr. (orgs.). A Botânica no Brasil: pesquisa, ensino e políticas públicas ambientais. Imprensa Oficial, São Paulo, pp. 655-659.

Torres, A.C., Linda, C.S. \& Ferreira, A.T. 1998. Retrospectiva da cultura de tecidos de plantas. In: A.C. Torres, C.S. Linda \& J.A. Buso (eds.). Cultura de tecidos e transformação genética de plantas. Embrapa Produção de Informação, Brasília, pp.11-20.

Vacin, E.F. \& Went, F.W. 1949. Some pH in nutrient solutions. Botanical Gazette 110: 605-617.

Van Den Berg, C. \& Chase, M.W. 2000. Nomenclatural notes of Laeliinae - I. Lindleyana 15: 115-119. 